\title{
DR. JUAN HUMBERTO ZAPATA GACITÚA IN MEMORIAM
}

\section{María Teresa Aedo Fuentes*}

\section{Trayectoria académica}

El Dr. Juan Humberto Zapata Gacitúa nació en 1955, en Lirquén, pequeña ciudad puerto de la bahía de Concepción. Cursó la Enseñanza Básica en la Escuela No 34 "Jorge Washington" de Concepción y la Enseñanza Media en el Instituto Superior de Comercio de Concepción, especialidad de Contabilidad, después de lo cual realizó estudios de Economía en la Universidad de Concepción. Sin embargo, su vocación humanista y su afición por la literatura lo motivaron a seguir la carrera de Profesor de Español en la Universidad de Concepción, donde se graduó en 1981. Prosiguió estudios de postgrado en la misma Universidad y obtuvo su grado de Magíster en Artes con mención en Literaturas Hispánicas en 1987. Luego, a fin de ampliar y fortalecer su formación, se trasladó a los Estados Unidos y recibió en 1990 el grado de Master of Arts en State University of New York at Stony Brook, donde continuó profundizando sus estudios de especialidad en literatura, hasta alcanzar el grado de Doctor of Philosophy en 1992. La investigación que lo condujo al grado llevó por título "La escritura crítico-reflexiva de Enrique Lihn: opción por la imaginación”, tema que se constituyó en uno de sus predilectos durante toda su trayectoria académica, al igual que los estudios sobre la postmodernidad cultural, filosófica, artística y literaria.

Al finalizar sus estudios de postgrado se incorporó como docente al Departamento de Español de la entonces Facultad de Educación, Humanida-

* Doctora en Literatura. Docente de la Facultad de Humanidades y Arte, Universidad de Concepción. Directora del Programa Multidisciplinario de Estudios de Género (PROMEG-UdeC), maaedo@udec.cl 
des y Arte de la Universidad de Concepción, donde continuó trabajando ininterrumpidamente hasta el momento de su fallecimiento. A lo largo de su carrera docente dictó cursos para la carrera de Pedagogía en Español y electivos de literatura abiertos para otras carreras de la Universidad de Concepción, centrados en temas de lírica y narrativa chilena e hispanoamericana contemporánea desde una perspectiva que vincula la creación literaria con los procesos históricos y culturales nacionales e internacionales. Desde los enfoques de los estudios culturales, ofreció durante varios años un curso sobre las "Relaciones entre el texto visual y el texto escrito", que abordaba las complejas relaciones semióticas entre estas textualidades en el mundo global. En el nivel de postgrado, el Dr. Zapata ofreció cursos de literatura y poesía chilena contemporánea para los niveles de Magíster en Literaturas Hispánicas y de Doctorado en Literatura Latinoamericana del Departamento de Español de la Facultad de Humanidades y Arte, que profundizaban aspectos de la escritura y la cultura expresados en títulos como: "La escritura de Enrique Lihn: crítica, poesía y narrativa", "Experiencias límite del lenguaje en la poesía chilena de los siglos XX y XXI", "Narrativa chilena contemporánea: proyectos terminales y de continuidad" y "Literatura y videósfera en la poesía chilena contemporánea”.

El Dr. Zapata ejerció también una permanente labor como formador de investigadores en la línea de literatura y poesía chilena a través de los seminarios de titulación de pregrado de la Carrera de Pedagogía en Español y de la dirección de tesis de postgrado en los programas de Magíster en Literaturas Hispánicas y Doctorado en Literatura Latinoamericana de la Universidad de Concepción. De la misma manera, en el marco de los programas de postgrado realizó un activo trabajo en los grupos de investigación "Literatura Chilena", del que fue Investigador y Coordinador Alterno entre los años 2003 y 2005, y en el Grupo de "Estudios Culturales de la Literatura Latinoamericana" que dirigió entre los años 2006 y 2013, que convocó a numerosos estudiantes e investigadores jóvenes.

Su dedicación a la literatura, tanto en su dimensión de teoría y análisis como de creación, lo motivaron a difundir permanentemente esta producción a través de la participación en seminarios, charlas y conferencias dirigidos a la comunidad universitaria y a la comunidad penquista a través de proyectos de extensión y en particular en las Escuelas de Verano realizadas 
cada año por la Dirección de Extensión de la Universidad; asimismo, mantuvo publicaciones derivadas de su estudio y actualización constante en lecturas sobre producción literaria en escritores chilenos. Su conocimiento y dedicación a la literatura se expresaron también en la Dirección de la revista Acta Literaria, que guió desde el año 2005 y que logró bajo su dirección la indexación en importantes registros internacionales de calidad de producción científica como Thomson Reuters (ex ISI).

Entre sus investigaciones formales merece destacarse el proyecto "La escritura de Enrique Lihn: expresión de una cultura chilena euro-hispano-americana", aprobado y financiado por el "Concurso Nacional Especial de Proyectos de Investigación de Postdoctorado 1993" de CONICYTFONDECYT, cuyo texto final fue recomendado para ser publicado como libro. Posteriormente, retomó esta temática para insertarla en la reflexión actual sobre teoría y creación literaria, desarrollando entre 2010 y 2014 el proyecto de investigación "Enrique Lihn en el siglo XXI: Desplazamientos teóricos, críticos y analíticos”, auspiciado por la Dirección de Investigación de la Universidad de Concepción.

Junto a la dimensión académica del quehacer del Dr. Zapata en torno a la literatura chilena, destaca con igual intensidad su dedicación a la creación poética, que inició desde muy joven y tuvo su época de mayor despliegue como integrante del grupo de poetas penquistas aglutinados en la revista Posdata, en los años ochenta del siglo XX. Este itinerario poético tuvo un momento culminante en la publicación de su libro de poesía titulado Interiores/Exteriores, editado en 2007 en Concepción por Cosmigonón Ediciones y prologado por Miguel Gomes, quien observó: "Con trazos discretos, fragmentados, la escritura de Juan Zapata dibuja un sujeto evanescente que puebla el mundo con la ubicuidad de los fantasmas". En efecto, nuestro querido colega habitaba el mundo de una manera silenciosa, pero tan innegablemente presente para todas las personas que lo conocieron y recorrieron con él diversos territorios geográficos, estéticos e intelectuales, que su recuerdo permanecerá entrelazado a nuestras vidas más allá de este In Memoriam que compartimos con admiración y afecto. 


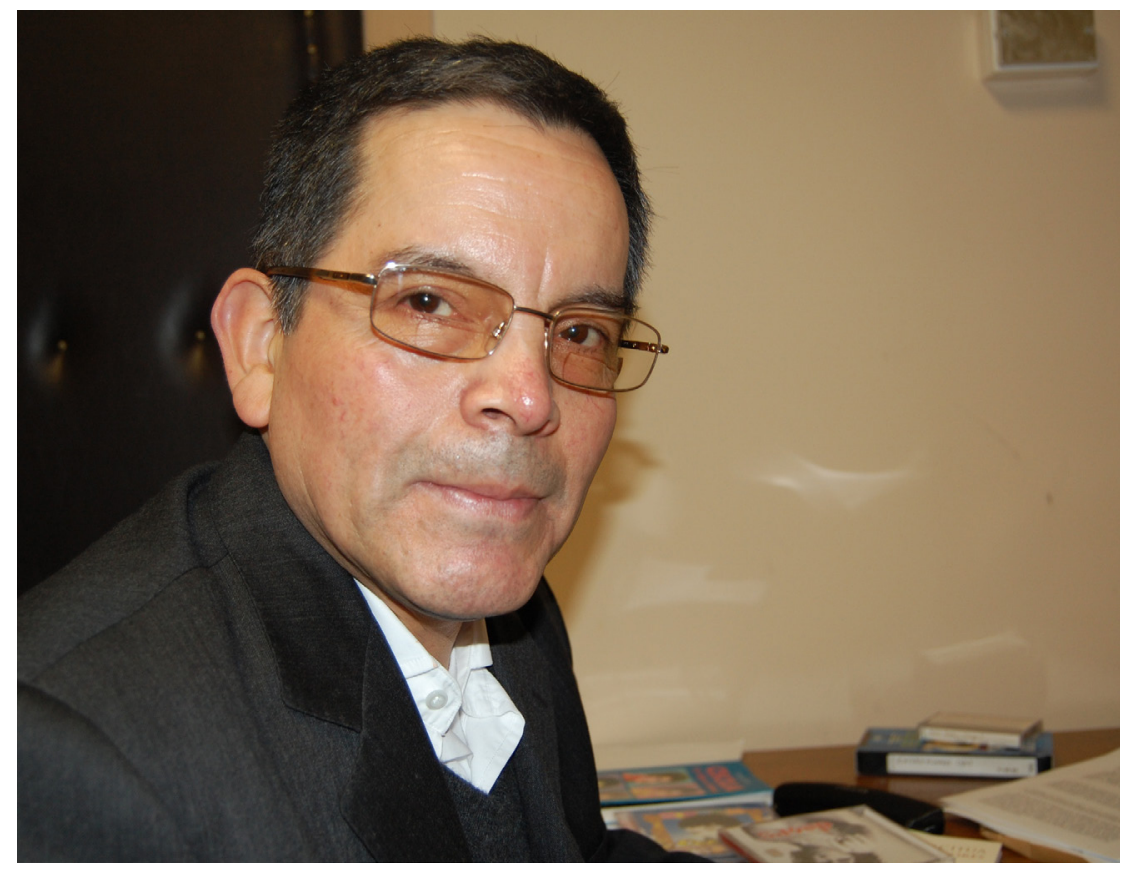

JuAN H. Zapata Gacitúa

(1955-2015) 


\section{Publicaciones relevantes}

1990: "Antología del cuento chileno de Pedro Lastra y Rigas Kappatos". Revista Chilena de Literatura, $\mathrm{N}^{\circ} 36$ (Noviembre), pp. 152-153.

1990: "Conversaciones con Enrique Lihn de Pedro Lastra". Inti $\mathrm{N}^{\circ} 31$, Providence College, Rhode Island, U.S.A. (Primavera), pp. 179-186.

1990: "Emilio Bejel y Ramiro Fernández: La subversión de la semiótica: análisis estructural de textos hispánicos". Revista Chilena de Literatura $\mathrm{N}^{\mathrm{O}} 35$ (Abril), pp. 160-164.

1990: "Señales de ruta de Juan Luis Martínez por Enrique Lihn y Pedro Lastra". Nuevo Texto Crítico $\mathrm{N}^{\circ}$ 5, Stanford University, California, U.S.A., pp. 216-218.

1990: "Veinte estudios sobre la literatura chilena del siglo veinte de Marcelo Coddou". Hispamérica $\mathrm{N}^{\circ}$ 55, Maryland, U.S.A. (Abril), pp. 131133 .

1991: "Enrique Lihn. Diario de muerte". Revista de Crítica Literaria Latinoamericana $\mathrm{N}^{0} 33$, University of Pittsburg, Pennsylvania, U.S.A. $\left(1^{\mathrm{er}}\right.$ semestre), pp. 326-327.

1991: "Poesía. Revista ilustrada de información poética". Revista Chilena de Literatura $\mathrm{N}^{\circ} 38$ (Noviembre), pp. 149-155.

1994: "Persona non grata de Jorge Edwards". Atenea No 469, pp. 177-179.

1994: "Excentricidad de la cultura hispanoamericana desde la perspectiva de Octavio Paz". Atenea $\mathrm{N}^{\circ}$ 470, pp. 69-82.

1994: Enrique Lihn: la imaginación en su escritura crítico-reflexiva. Santiago de Chile: Editorial La Noria.

1996: "Beata Beatrix de Enrique Lihn: la escritura como rito y recorrido por el Purgatorio". En Barraza, E. (Ed.), Estudios de literatura chilena e hispanoamericana contemporánea (pp. 225-231). Osorno, Chile: Editorial Universidad de Los Lagos.

1997: "Intertextos de la escritura de Enrique Lihn. La realidad como signo: la vida como textualidad de base". En Monasterios P., E. (Ed.), Con tanto tiempo encima. (Aportes de literatura latinoamericana en homenaje a Pedro Lastra) (pp. 391-402). La Paz, Bolivia: Plural Editores.

1998: "Enrique Lihn. El circo en llamas: una crítica de la vida". Posdata, $\mathrm{N}^{\circ \mathrm{s}} 1$ y 2 , pp. 135-138. 
1999: "Prólogo". En Novoa, P. y Ojeda, J. (Eds.), 1999 Concepción Antología poética. Tomé: Ediciones Mala Face, pp. 7-16.

2004: "Fragmentos teórico-críticos: textos chilenos". Fragmento: "Respecto al libro". En http:/www2.udec.cl/-docliter/mecesup/grupos.htm 2005: "Escribir sobre el último libro de Enrique Lihn". Revista electrónica Nibula. En http://www2.udec.cl/nibula/

2007: "Prólogo". En Triviños, G. y Oelker, D. (Eds.), Crítica y creatividad. Acercamientos a la literatura chilena y latinoamericana (pp. 9-21). Concepción, Chile: Editorial Universidad de Concepción.

2008: "La narrativa de Enrique Lihn: expresión de un referente cultural complejo". Taller de Letras Vol. 1, No 42, pp. 23-42.

2008: "Los más allá de la escritura poética de Oscar Hahn". Hofstra Hispanic Review Vol. 3, Nº 7, pp. 39-52.

2011: "Actualización crítica y teórica de la dimensión visual en la escritura y en la obra creativa de Enrique Lihn". En Miranda Herrera, P. y Fuentes-Vásquez, C. L. (Eds.), Chile mira a sus poetas (pp. 174-186). Facultad de Letras, PUC. Santiago: Editorial Pfeiffer.

2011: "Doce años de escritura en todos los géneros" (Conferencia de Enrique Lihn). Anales de Literatura Chilena $\mathrm{N}^{\circ}$ 16, pp. 183-201.

2012: "Derechos de autor, el no libro de Enrique Lihn". Anales de Literatura Chilena $\mathrm{N}^{\circ} 18$, pp. 117-133. 


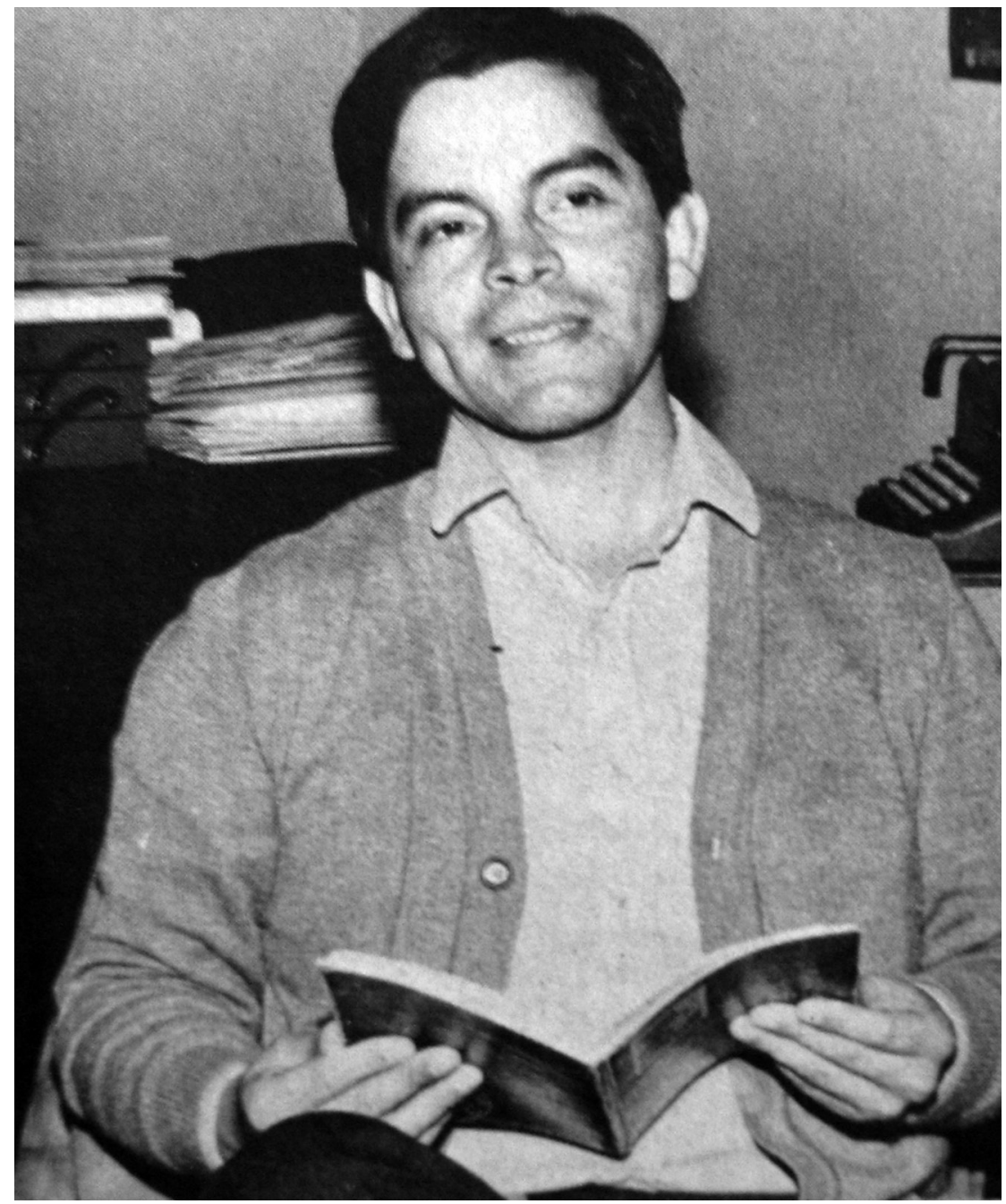

El profesor Juan Zapata Gacitúa en los años 80. (Fotografía diario El Sur). 